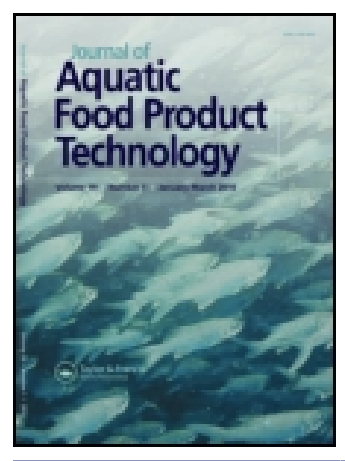

Journal of Aquatic Food Product Technology

\title{
Quality Evaluation of Alaska Pollock (Theragra chalcogramma) Roe by Image Analysis. Part II: Color Defects and Length Evaluation
}

\author{
Murat O. Balaban, Mélanie Chombeau , Bahar Gümüş \& Dilşat Cırban
}

To cite this article: Murat O. Balaban, Mélanie Chombeau, Bahar Gümüș \& Dilșat Cırban (2012) Quality Evaluation of Alaska Pollock (Theragra chalcogramma) Roe by Image Analysis. Part II: Color Defects and Length Evaluation, Journal of Aquatic Food Product Technology, 21:1, 72-85, DOI: $10.1080 / 10498850.2011 .583378$

To link to this article: http://dx.doi.org/10.1080/10498850.2011.583378

\section{曲 Published online: 23 Jan 2012.}

\section{Submit your article to this journal $\widetilde{ }$}

Џ Article views: 78 


\title{
Quality Evaluation of Alaska Pollock (Theragra chalcogramma) Roe by Image Analysis. Part II: Color Defects and Length Evaluation
}

\author{
MURAT O. BALABAN, ${ }^{1}$ MÉLANIE CHOMBEAU, ${ }^{2}$ \\ BAHAR GÜMÜŞ, ${ }^{3}$ AND DILŞAT CIRBAN ${ }^{4}$ \\ ${ }^{1}$ Chemical and Materials Engineering Department, University of Auckland, \\ Auckland 1142, New Zealand \\ ${ }^{2}$ Agricultural Engineering School, ESITPA, Mont Saint Aignan, France \\ ${ }^{3}$ School of Fisheries, Akdeniz University, Dumlupınar Bulvarı, \\ Antalya, Turkey \\ ${ }^{4}$ Izmir Institute of Technology, Gülbahçe Köyü-Urla, İzmir, Turkey
}

\begin{abstract}
In the second part of the study of the quality evaluation of pollock roe by image analysis, methods to quantify the color defects (green spots, dark strips, dark color, and uneven coloring due to "freezer burn") were developed. Dark roes can be detected by their average $L^{*}$ value. Dark strips can be detected by quantifying the percentage of pixels that have an $L^{*}$ value below an $L^{*}$ threshold. Since there is wide variation among the average colors of the roes, this $L^{*}$ threshold value must be auto-adjusting to the color of the individual roe. Green spots can be detected by their darker color and by ignoring

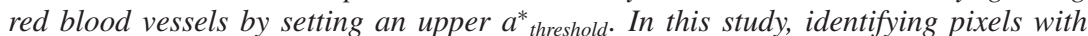
$L^{*}$ values less than the $L^{*}$ threshold $=66 \%$ of the $L^{*}$ average of the roe, and $a^{*}$ values less than an $a^{*}$ threshold $=20$ successfully detected dark strips and green spots. Detection and quantification of uneven color and "freezer burn" required a "smoothing" of the roe colors to reduce details. The "color primitives" method was used, with a setting of a color threshold $(C T)=75$. The resulting images were analyzed by setting $L^{*}$ threshold values of 60,65, 70, 75, 80, and $85 \%$ of $L^{*}{ }_{\text {average }}$ of individual roes. More surface area of the roe was judged as defective with increasing $L^{*}$ threshold. With proper selection of

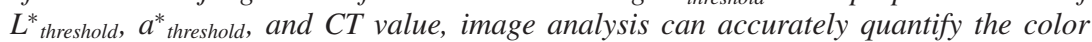
defects of pollock roe.

Practical Application Abstract: Automation of pollock roe sorting by color would streamline the operation, reduce error rates, and help with standardization of quality. Combined with other capabilities of machine vision such as sorting by weight, this technology can be used for multiple purposes simultaneously.
\end{abstract}

Keywords image processing, pollock roe, green spot, color defect, freezer burn

The authors would like to thank Westwards Seafoods, Inc.--especially Mr. Hiroyuki Kozuma, Vice President of Operations; Mr. Mitch Kilborn, General Manager; and Mr. Chris Sannito, QC Manager-for allowing the use of their plant and their pollock roe for the study. Partial funding was provided by the University of Alaska Fairbanks.

Address correspondence to Murat O. Balaban, Department of Chemical and Materials Engineering, University of Auckland, 20 Symonds Street, Auckland 1142, New Zealand. E-mail: MuratKodiak@gmail.com 


\section{Introduction}

The Alaska pollock fishery is the largest U.S. fishery by volume. Annual catches from 2000-2009 have averaged around 1.3 million metric tons (National Marine Fisheries Service [NMFS], 2010). This fishery accounts for more than one-third of total U.S fisheries landings and about $7 \%$ of total U.S. ex-vessel value. The revenues from roe account for about one-third of all pollock products, while the volume of roe in the total pollock products is about 5\%. In 2008, the United States exported 19,825 metric tons of frozen Alaska pollock roe (NMFS, 2009). Approximately $96 \%$ of the frozen roe was exported to Japan and South Korea.

The traditional quality evaluation of pollock roe is done by human graders following a complicated set of criteria based on whether the roe is a single or double roe and based on its weight, intactness, color defects, and maturity, as discussed in Part I of this study (Balaban et al., 2012). For weight classification, the error rate was calculated as $13 \%$ by human graders. The evaluation and quantification of color is more difficult, and this study shows that both sides of the roe may not have the same colors and/or defects, making evaluation more complicated.

Quality evaluation can be automated by machine vision (MV), and this is desirable for a more rapid, objective, and repeatable process (Balaban et al., 1994; Luzuriaga et al., 1997; Brosnan and Sun, 2002). MV methods have been developed for different products and are being used increasingly in the food industry for quality assurance, with a high level of flexibility and repeatability at relatively low cost (Gunasekaran, 1996; Balaban and Odabaş1, 2006). MV has been applied to many foods, such as quality grading of fruits (Blasco et al., 2003) and for the quality analysis of meat, fish, pizza, cheese, and bread (Brosnan and Sun, 2004; Tan, 2003).

Quantification of color by humans is difficult (Balaban et al., 2008). MV can evaluate color, but specific criteria for each application need to be developed, and the method must be flexible to account for the variability of food and agricultural materials. Bekhit et al. (2009) evaluated the color parameters (lightness $\mathrm{L}^{*}$, redness a*, yellowness $\mathrm{b}^{*}$, chroma $\mathrm{C}^{*}$, and hue $\mathrm{h}^{*}$ ) and spectral surface reflectance of raw and processed roes from chinook salmon, hoki, southern blue whiting, hake, blue warehou, and barracouta. Beatty (1993), Beatty et al. (1993), Croft et al. (1996), and Kurnianto et al. (1999) developed a twodimensional contour shape analysis method to automate herring roe quality grading by MV. Herring roe has a single skein (sac that holds individual eggs), compared to either a single or a double skein for pollock roe. In addition, there are color-based defects that need to be detected in pollock roe (Bledsoe and Rasco, 2006). These include green spots, dark roes, dark strips, and uneven colors due to darkening of part of the surface by "freezer burn." This is the drying of the surface during frozen storage, mostly due to inadequate packaging, that results in a darkening of the color. The analysis of the surface color of pollock roe is also complicated by the existence of blood vessels in the membrane that surrounds the eggs. Since the membrane is removed when the eggs are processed, these blood vessels do not constitute a defect, but their presence complicates color analysis. Also, one side of the roe may have a different color than the other side, and defect(s) may be only on one side. Therefore, both sides of the roe must be evaluated for quality.

The automation of the complete quality evaluation of pollock roe would require the following steps: the determination of shape (single or double roe, intactness); the determination of weight; the determination of the maturity of the roes; and the quantification of visual/color defects such as green spots, dark roes, etc. These steps are interconnected, as discussed in Part I of this study. For example, the weight classification depends on single or double roes, on intactness, and on maturity. 
MV grading to determine the quality of Alaska pollock roe is desirable to increase the reliability and uniformity of grading, with the possibility of non-destructively analyzing several parameters simultaneously such as weight prediction, detection of non-uniform size, and color defects. With this in mind, the objectives of the second part of this study were (a) to develop automated criteria to evaluate and quantify the color defects (green spots, dark strips, and dark color) and (b) to quantify uneven color development due to "freezer burn" for Alaska pollock roe with the aim of automated sorting using MV.

\section{Materials and Methods}

\section{Roe}

The same one hundred and forty-two Alaska pollock (Theragra chalcogramma) roes described in the first part of this study were used (Balaban et al., 2012). The roes were already graded by plant personnel and placed in their appropriate bins in the processing line in a Kodiak, AK processing plant. They were temporarily removed from their bins, and their image obtained by placing them in a light box described by Luzuriaga et al. (1997). The roe was then returned to the processing line. The roes were chosen at random within a grade, and we tried to have about 10 roes per quality grade, depending on availability.

\section{Imaging}

A light box, designed and built by the researchers and described by Luzuriaga et al. (1997) — with the dimensions 122-cm high, 61-cm wide, and 46-cm deep-was placed in the plant, close to the roe processing line. The light box had D65 illumination using fluorescent bulbs with a Color Retention Index of 0.98 (F15W1XX, Lumiram, Larchmont, NY, USA). The door of the light box was closed during image acquisition to eliminate interference from ambient light. The roe was placed under a DFK 31BF03 video camera (The Imaging Source, Charlotte, NC, USA) with a $1024 \times 768$ pixel resolution, and a IEEE1394 interface to a laptop computer. The camera had a Tamron F: 6-12 mm, 12VM 612 lens (Tamron USA, Commack, NY, USA). The camera settings were calibrated by minimizing the cumulative error for eight colors (red, green, blue, yellow, magenta, cyan, black, white) that correspond to the eight corners of the Red, Green, Blue (RGB) color space (Table 1). Reference colors (Color Checker Classic, X-rite Inc., Grand Rapids, MI, USA) were used for this.

Four images were acquired for the same roe in the light box, to compare if the angle and side of the roe had an impact on the results. Images were taken from two different

Table 1

Settings of the video camera

\begin{tabular}{lc}
\hline Setting & Specifications \\
\hline Brightness & 32 \\
Hue & 169 \\
Saturation & 102 \\
Exposure & -2 \\
Gamma & 10 \\
Contrast & 585 \\
White balance & 56 \\
\hline
\end{tabular}




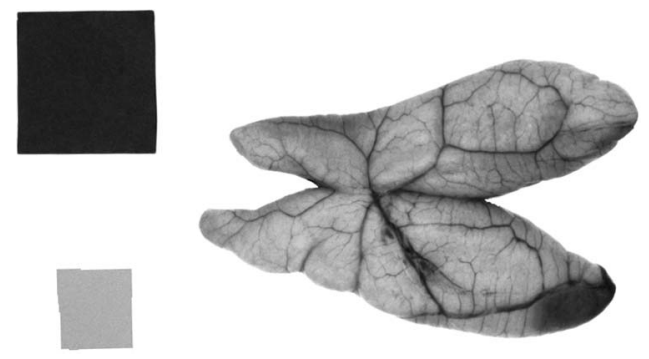

Figure 1. Image of Alaska pollock roe taken in the light box, with the reference squares for size (black) and for color.

angles for the roe, then it was flipped to the other side, and the process was repeated. Every image included two reference squares, one for size and the other to calibrate for color (Figure 1). The color reference was from Color Checker.

\section{Image Preparation}

After segmentation (differentiation of the roe from the background) by using threshold RGB values, color calibration was performed using the image acquisition and analysis software LensEye (Engineering and CyberSolutions, Gainesville, FL, USA). The known colors of the reference square $\left(\mathrm{L}^{*}=52.14, \mathrm{a}^{*}=38.68, \mathrm{~b}^{*}=22.35\right)$ were compared with the average color $\left(\mathrm{L}^{*}, \mathrm{a}^{*}\right.$, and $\left.\mathrm{b}^{*}\right)$ of the reference square obtained from the image. The difference was applied to every pixel of the image, resulting in color calibration.

\section{Preliminary Analysis to Determine the $L^{*}$ and $a^{*}$ Thresholds}

The color of roes had a wide distribution. The $\mathrm{L}^{*}$ ranged from less than 15 to more than 85 (Figure 2). Since the green spots and the dark strips are "darker" than the rest of the

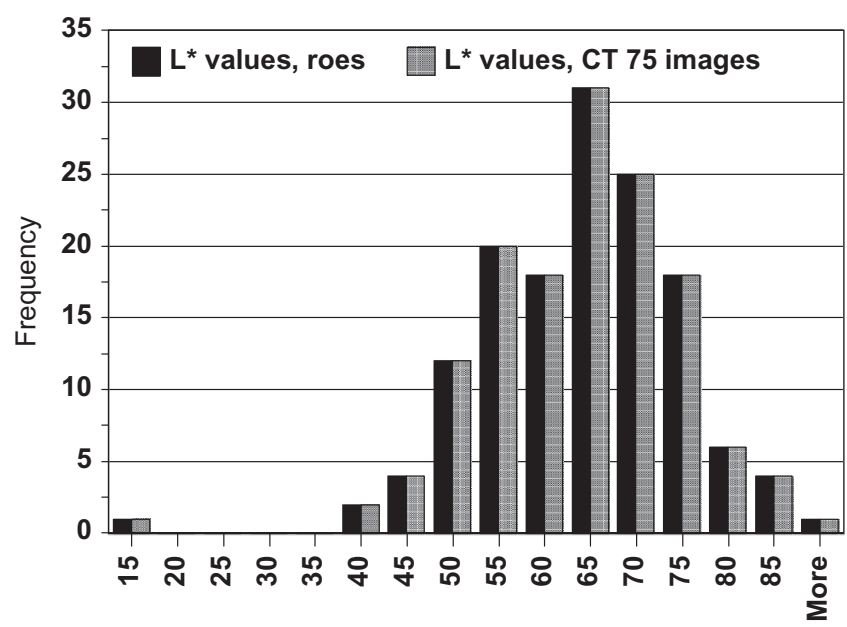

Average $L^{*}$ values of roes

Figure 2. Distribution of $\mathrm{L}^{*}$ values. There were 142 roes, each with four images, and the $\mathrm{L}^{*}$ values were averaged for these four images. CT 75 refers to the "color smoothing" of the image by selecting a "color primitive" threshold of 75 . 
roe, they can be detected by looking at an appropriate $\mathrm{L}^{*}$ threshold below which a color defect is assumed. However, the selection of this $\mathrm{L}^{*}$ threshold is complicated by the fact that the average $\mathrm{L}^{*}$ value of the roe varies widely. Therefore, the $\mathrm{L}^{*}$ threshold must "adapt" to each roe's color. The easiest approach is to take the $\mathrm{L}^{*}$ average of each roe and then reduce it by a percentage to find the $\mathrm{L}^{*}$ threshold. Another concern is the red blood vessels that are darker than the rest of the roe, but that do not constitute a defect and therefore must not be detected as a color defect. The solution to this was to limit the detection of a defective pixel color to below an appropriate $\mathrm{a}^{*}$ threshold. Higher $\mathrm{a}^{*}$ values mean "more red," which would eliminate the detection of the blood vessels.

Thirty-seven roes representing the color and defects range were selected. They were analyzed using the LensEye software by applying different percent reductions to the $\mathrm{L}^{*}$ average of each roe and different $\mathrm{a}^{*}$ threshold values. The area detected as defective by using a given set of $\mathrm{L}^{*}$ threshold and $\mathrm{a}^{*}$ threshold was shown in real time on the image for evaluation of appropriate selection. It became evident that the level of $66 \%$ reduction of the $\mathrm{L}^{*}$ average and $\mathrm{a}^{*}$ threshold $=20$ were the best choices (data not shown). These values were adopted to analyze all 142 roes for "color defects" that included green spots and dark strips.

\section{Quantification of Defective Surface}

All 142 roe images, each image containing four pictures of the same roe at different angles for both sides, were analyzed using the color defect settings of $\mathrm{L}^{*}$ threshold $=0.66 \times \mathrm{L}^{*}$ average of each picture in the image and $\mathrm{a}^{*}$ threshold $=20$. The images showing the highlighted defective areas were saved.

\section{Color-Smoothing of the Image}

The darkening of part of the surface of the roe due to "freezer burn" is difficult to detect by the above settings. "Smoothing" of the colors was necessary to average small differences in color and therefore make detection of uneven dark areas easier. The method chosen to accomplish this was the "color primitives," described by Balaban (2008).

A color primitive is defined as a continuous area of an image where the "intensity" of any pixel is within a given color threshold (CT) value. The intensity difference is defined as:

$$
\Delta I=\sqrt{\left(R-R_{i}\right)^{2}+\left(G-G_{i}\right)^{2}+\left(B-B_{i}\right)^{2}} .
$$

The R, G, and B values are those of an "anchor or reference pixel," and the values with the subscript $\mathrm{i}$ are the neighboring pixels being tested for belonging to the primitive. Once all the pixels that belong to a primitive with $\Delta \mathrm{I}$ values less than a given threshold are found and no other pixels can be added, then the anchor pixel is changed to an available, neighboring pixel, and the process is repeated until all pixels are processed. The $\Delta \mathrm{I}$ parameter is important: a small value will result in many small primitives; a large value will result in a lower number of larger primitives.

The color of the primitive is the average color of all the pixels that it contains. Therefore, this is a "smoothing" technique for color. After many trial-and-error runs, a $\mathrm{CT}=75$ value was found to smooth the images appropriately. All roe images were processed in this manner, and the resulting smoothed images were analyzed. 


\section{Analysis of the Smoothed Images}

The images that were color-smoothed by applying CT $=75$ were analyzed by using the criterion of determining as the defective area if a pixel had an $\mathrm{L}^{*}$ value below the $\mathrm{L}^{*}$ threshold value (darker). The $\mathrm{L}^{*}$ threshold values were selected as $\mathrm{L}^{*}$ threshold $=\mathrm{L}^{*}$ average of the roe $\times \mathrm{P} \%$ $(60,65,70,75,80$, and $85 \%$ were used for the $\mathrm{P}$ value $)$. The resulting percent defective area was calculated by the LensEye software, and the image showing this area was saved. The frequency distributions of the percent defective areas were developed for each level of P.

\section{Evaluation of Length Differences of the Two Sides of a Double Roe}

For double roes (64 double roes in this study), the length of the two sides is evaluated; if there is a difference of more than, e.g., 20\%, then the roe is considered as defective. To estimate the length of the sides, the "distance transform" method was used to calculate the medial axis of the sides (Fabbri et al., 2008). Then the relative lengths were compared, and a percent difference was calculated as:

(Length of the long side - length of the short side)/Length of the long side * 100 .

A typical medial axis is shown in Figure 9. Since there were generally four images of the same roe, two approaches were taken: first, each individual image was treated separately, and then the average percent difference of a roe (generally the average of four values) was analyzed.

\section{Results and Discussion}

\section{Quantification of Green Spots, Dark Stripes, and Dark Roes}

The identification of dark roes was done by examining the average $\mathrm{L}^{*}$ value of the roe. In our study, the roes had a wide range of colors. The average $\mathrm{L}^{*}$ distribution is shown in

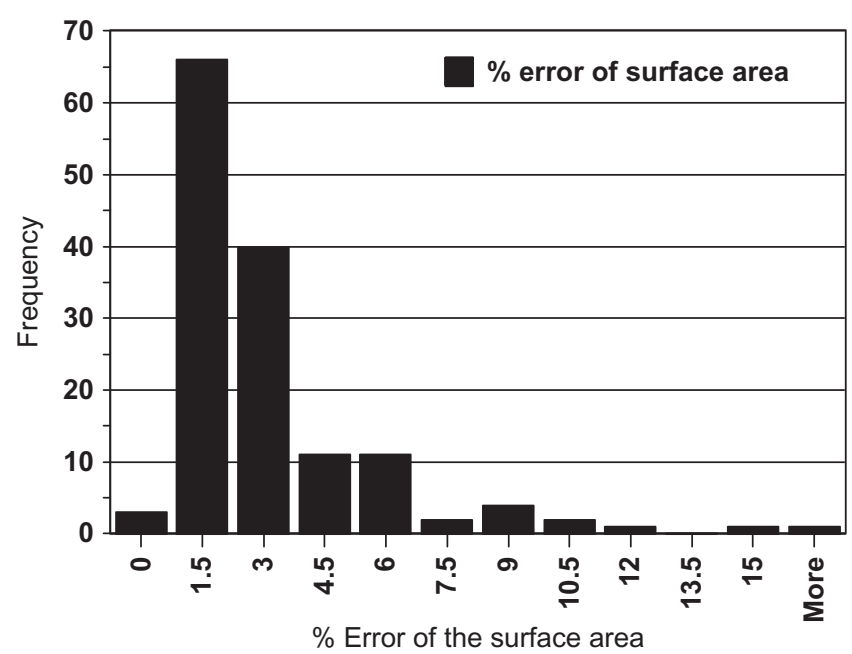

Figure 3. Distribution of the percent of the surface area (in the worst case picture among the four pictures for each roe) determined to be a color defect using settings: $\mathrm{L}^{*} \leq \mathrm{L}^{*}$ threshold $=0.66 \times \mathrm{L}^{*}$ average of the roe picture, and $\mathrm{a}^{*} \leq 20$. 


$$
\begin{aligned}
& \text { ass } \\
& \begin{array}{l}
\text { ave } \\
\text { ave } \\
\text { ave }
\end{array}
\end{aligned}
$$


Table 2

$\mathrm{L}^{*}$ values and \% defective surfaces of roes shown in Figures 4, 5, and 6

\begin{tabular}{lcrr}
\hline & $\begin{array}{c}\text { Roe 1, } \\
\text { Figure 4 }\end{array}$ & $\begin{array}{c}\text { Roe 39, } \\
\text { Figure 5 }\end{array}$ & $\begin{array}{c}\text { Roe 115, } \\
\text { Figure 6 }\end{array}$ \\
\hline Average $\mathrm{L}^{*}$ of four images & 14.61 & 48.75 & 36.99 \\
\% of surface determined as color defect & 15.03 & 4.63 & 2.44 \\
CT 75; \% defective surface; $\mathrm{L}^{*}$ threshold $=60 \%$ of $\mathrm{L}^{*}$ av & 21.77 & 10.24 & 10.05 \\
CT 75; \% defective surface; $\mathrm{L}^{*}$ threshold $=70 \%$ of $\mathrm{L}^{*}{ }_{\text {av }}$ & 57.88 & 10.25 & 32.96 \\
CT 75: \% defective surface; $\mathrm{L}^{*}$ threshold $=80 \%$ of $\mathrm{L}^{*}$ av & 86.19 & 10.25 & 33.49 \\
\hline
\end{tabular}

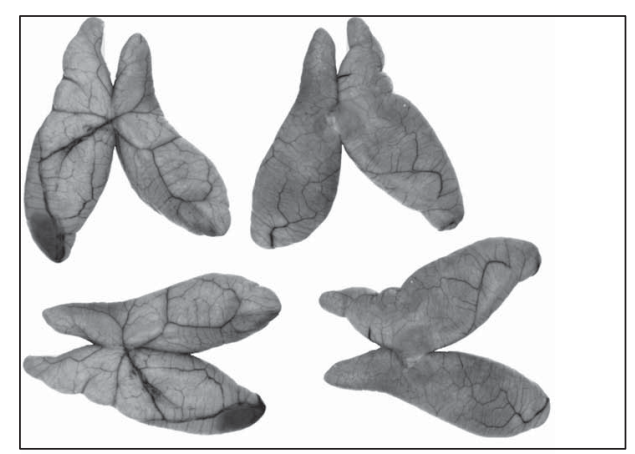

(a)

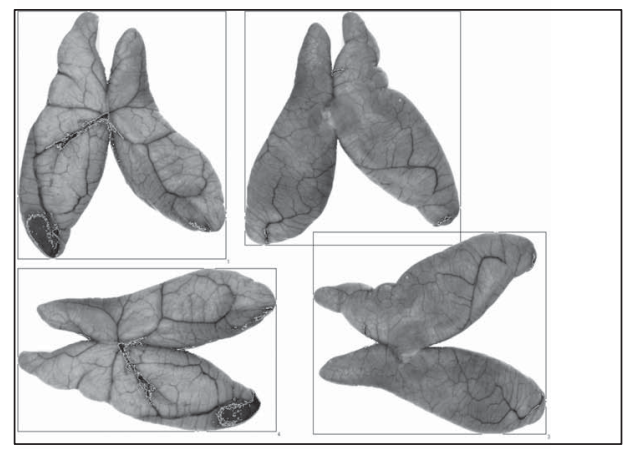

(b)

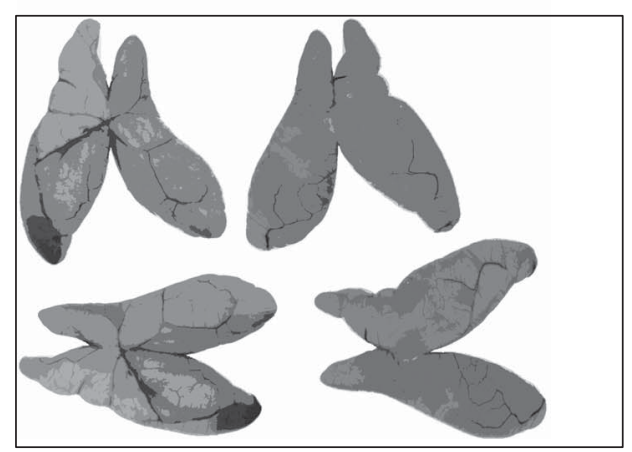

(c)

Figure 5. Example of a roe with green spot and dark strip. 


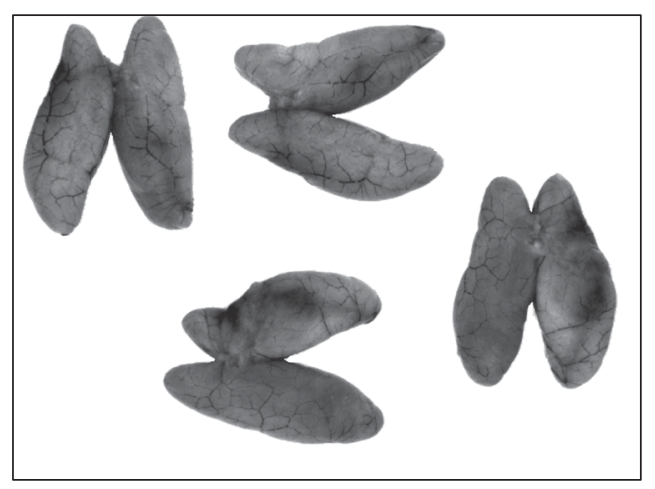

(a)

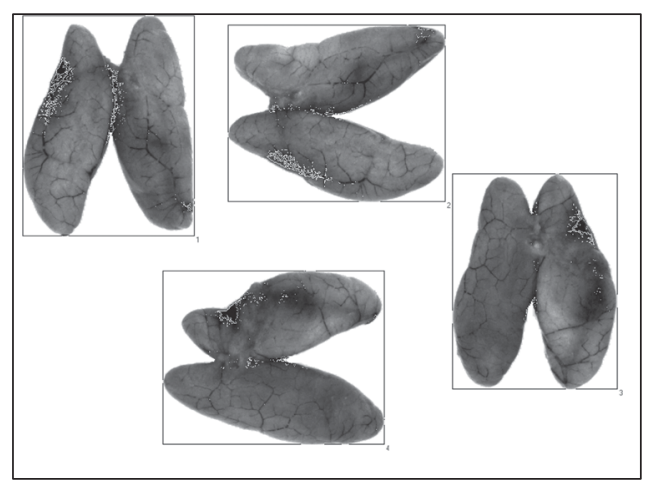

(b)

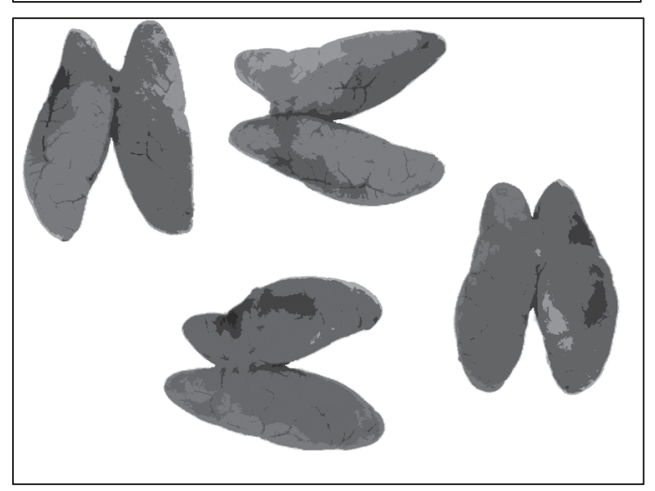

(c)

Figure 6. Example of a roe with uneven color, caused by "freezer burn."

Figure 4 shows an example of a dark roe. The results of various analyses of this roe are shown in Table 2. This roe had an $\mathrm{L}^{*}$ average of 14.61 . It was the darkest roe in the samples. The result of the color defect analysis for this roe is shown in Figure 4b. The areas highlighted in white constitute the region of color defects and were $15 \%$ (worst case of four pictures) of the area of the roe.

Figure 5a shows an example of a roe with green spots and dark strips. The dark strips are visible on the roe picture at the upper left corner. Also, the presence of dark blood vessels is noticeable. In Figure 5b, the areas highlighted in white are considered as a color defect and constitute $4.6 \%$ of the roe's surface area (Table 2). This includes the dark strip. It should be noticed that the blood vessels are not included in the defective areas, as expected. 
Figure 6a shows an example of a roe with an uneven color and with darkening due to "freezer burn." The dark areas are most visible on the bottom and rightmost pictures. The amounts of color defective areas are shown in Figure $6 \mathrm{~b}$ (2.4\% of the area, Table 2). It should be noted that the dark areas are not caught by the $\mathrm{L}^{*}$ threshold and $\mathrm{a}^{*}$ threshold settings. This is why the next step, the "smoothing" of the colors for uneven color detection, was performed.

\section{Detection of Uneven Colors}

All the images were subjected to a $\mathrm{CT}=75$ color primitive "smoothing." Since this is smoothing by averaging, the average $\mathrm{L}^{*}$ value of the roe does not change (Figure 2 ). The resulting images can be seen in Figure $4 c, 5 c$, and $6 c$. It should be noticed in these Figures that the degree of detail is much less, but the general features are still intact.

The $\mathrm{CT}=75$ images were analyzed for $\%$ areas where the $\mathrm{L}^{*}$ value of a pixel was less than the $\mathrm{L}^{*}$ threshold $=\mathrm{L}^{*}$ average $\times \mathrm{P}$, where the percentage $\mathrm{P}$ was selected at $60,65,70$, 75,80 , and $85 \%$. The frequency distribution of the $\%$ areas detected for $\mathrm{P}=60,70$, and $80 \%$ are shown in Figure 7. As expected, as the $\mathrm{P}$ value increases, more of the surface area is detected and the defective area increases. However, if the roe only has uneven colors and no other defects, then the defective area does not increase when the $\mathrm{P}$ value goes from 60 to 80. This is shown in Figure 8. For the unevenly colored roe in Figure 6, the $\mathrm{P}=60$ analysis result is shown in Figure $8 \mathrm{a}, \mathrm{P}=70$ in Figure $8 \mathrm{~b}$, and $\mathrm{P}=80$ in Figure $8 \mathrm{c}$. The corresponding numbers for the defective areas are shown in Table 2. It is evident that for the unevenly colored roe, the defective area is the same regardless of the selection of the $\mathrm{P}$ percentage in color analysis. This is not the same for roes in Figures 5 and 6 . In their case, in the analysis of the $\mathrm{CT}=75$ images, as the P percentage increases, so does the defective area. This provides a tool for discriminating between a roe that has only uneven coloring and one that has other defects.

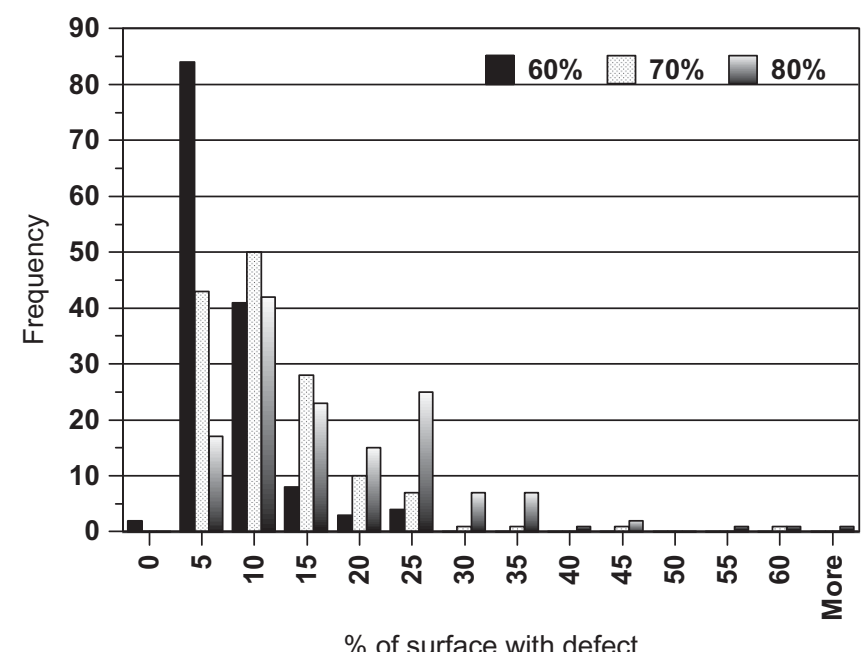

Figure 7. Frequency distribution of maximum percent of the surface area determined to be a color defect by using settings of $\mathrm{L}^{*}<\mathrm{L}^{*}$ threshold $=\mathrm{C} \times \mathrm{L}_{\text {average, }}^{*}$, where $\mathrm{C}=60,70$, and $80 \%$ in $\mathrm{CT}$ 75 images. 


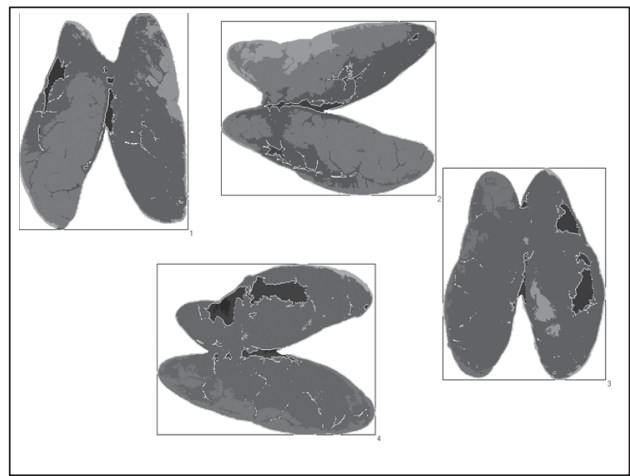

(a)

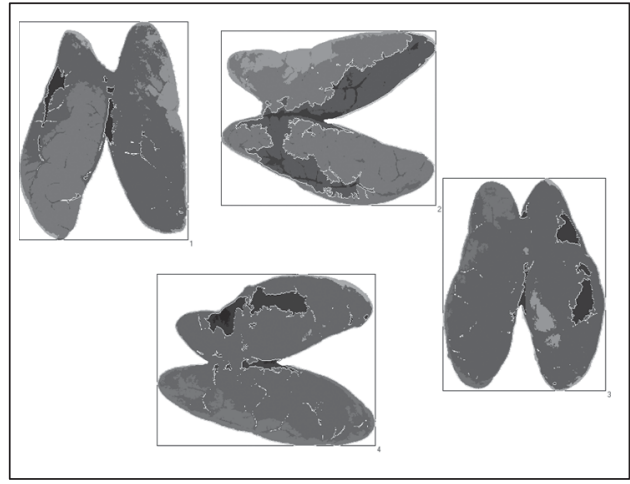

(b)

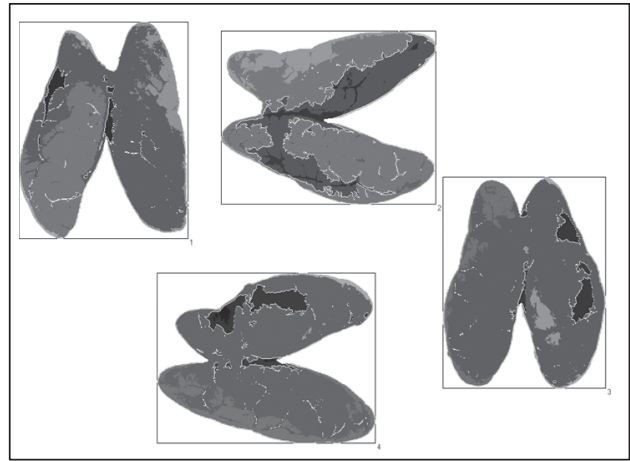

(c)

Figure 8. Defect evaluation of color-smoothed roe in Figure 6, using $\mathrm{L}^{*} \leq \mathrm{L}^{*}$ threshold $=\mathrm{C} \times \mathrm{L}_{\text {average }}$. where $\mathrm{C}=60$ (a), 70 (b), and $80 \%$ (c).

\section{Evaluation of Length Differences of the Two Sides of a Double Roe}

Figure 10 shows the histograms of the percent differences in lengths of the two sides of double roes in this study. When individual roe images were treated separately, there were wide variations for the same roe. This was because, depending on the placement of the roe and its side, there could be differences in appearance and therefore length. When all the percent differences of a roe were averaged (generally four values), then the level variation was reduced, as expected. This emphasizes the importance of placement of the roe on a conveyor belt, which affects how it is perceived. 


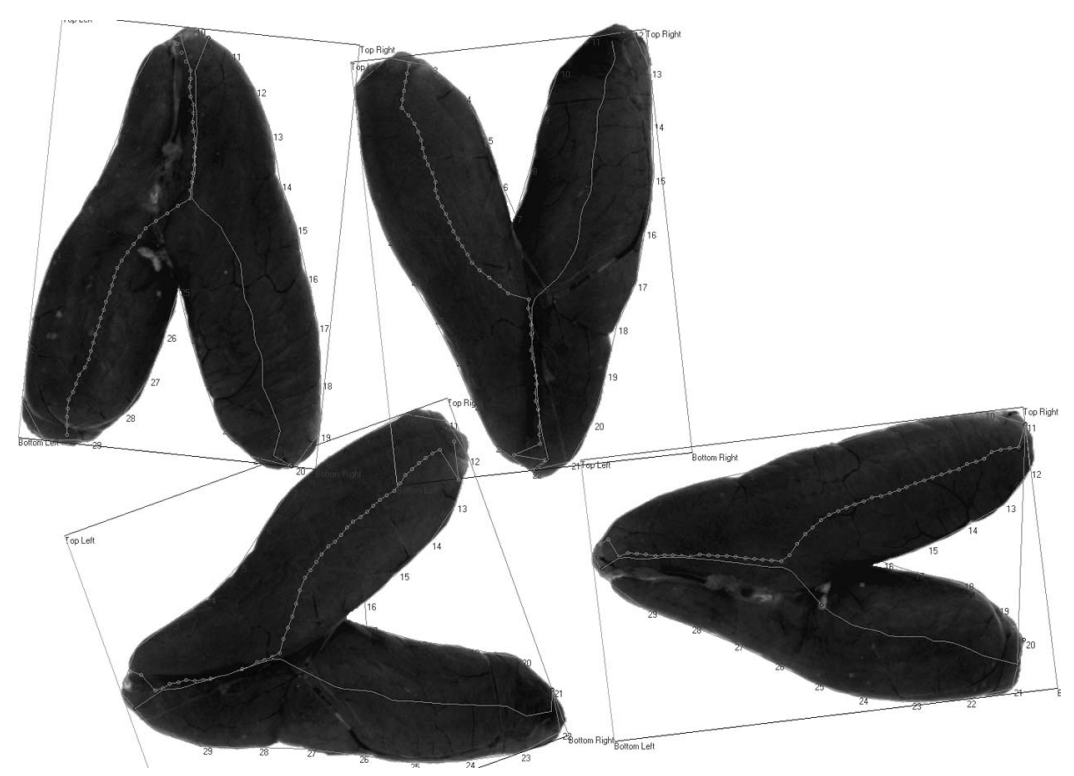

Figure 9. Example of medial axis determination of the two sides of the roe by using the "distance transform" method. Depending on the side, placement, and orientation, the length of the same side varied.

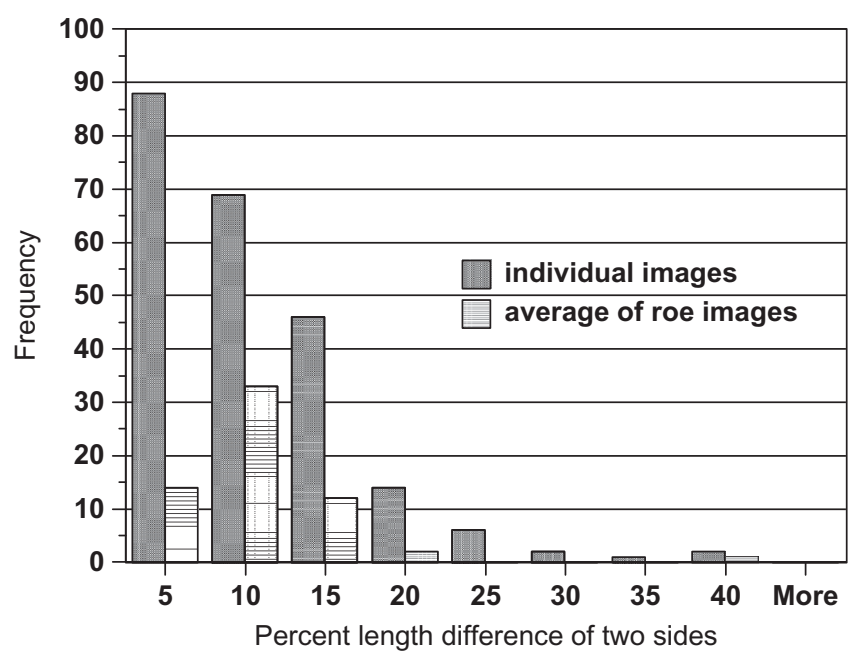

Figure 10. Frequency distribution of percent difference in the lengths of the two sides of a double roe. The typical threshold is $20 \%$ for the roe to be considered as defective.

\section{Conclusion and Recommendations}

The procedures developed in this study provide tools for the automation of color evaluation of pollock roe. The detection of dark roes is accomplished by setting a threshold for the average $\mathrm{L}^{*}$ value of the roe. The advantage of this is its flexibility in adapting to different colors changing from roe-to-roe, from season-to-season, and from location-to-location, since the inherent property of the roe, its average $\mathrm{L}^{*}$ value, is used for the determination of 
the $\mathrm{L}^{*}$ threshold. The quantification of green spots and dark strips requires the adjustment of two parameters: a percent of reduction of $\mathrm{L}^{*}$ average of the roe to determine the $\mathrm{L}^{*}$ threshold, and an $\mathrm{a}^{*}$ threshold value to eliminate interference of blood vessels. The quantification of uneven colors is a two-step process: first, the image is "color-smoothed" by applying an appropriate $\mathrm{CT}$ value, then the resulting image is analyzed for dark regions by setting an $\mathrm{L}^{*}$ threshold value based on an appropriate percentage of the $\mathrm{L}^{*}$ average of the roe. All these parameters can easily be adjusted depending on how severe the judging criteria are desired to be.

The "distance transform" method could be applied successfully to determine the length of a non-uniform shape such as a double roe. The challenge is to develop a method to capture images of both sides of the roe in an industrial setting and to present the roes consistently to the camera.

Combined with the methods and results of Part I in determining weight, the methods developed in this Part represent a significant step toward automation of the quality evaluation of pollock roe. The remaining work is in the area of automated maturity determination.

\section{References}

Balaban, M. O. 2008. Quantifying non-homogeneous colors in agricultural materials. Part I: Method development. J. Food Sci. 73(9): S431-S437.

Balaban, M. O., Aparicio, J., Zotarelli, M., and Sims, C. 2008. Quantifying non-homogeneous colors in agricultural materials. Part II: Comparison of machine vision and sensory panel evaluations. J. Food Sci. 73(9): S438-S442.

Balaban, M. O., Bergmann, Y., Yeralan, S., and Otwell, W. S. 1994. Determination of count and uniformity ratio of shrimp by machine vision. J. Aquat. Food Prod. T. 3(3): 43-58.

Balaban, M. O., Chombeau, M., Gümüş, B., and Cirban, D. 2012. Quality evaluation of Alaska pollock (Theragra chalcogramma) roe by image analysis. Part I: Weight prediction. J. Aquat. Food Prod. T. 21(1): 59-71.

Balaban, M. O., and Odabaş1, A. Z. 2006. Measuring color with machine vision. Food Technol. 60: 32-36.

Beatty, A., Gosine, R. G., and de Silva, C. W. 1993. Recent developments in the application of computer vision for automated herring roe assessment. IEEE Pac. Rim 2: 698-701.

Beatty, D. A. 1993. 2-D contour shape analysis for automated herring roe quality grading by computer vision. Unpublished master's thesis, University of British Columbia, Vancouver, British Columbia, Canada.

Bekhit, A. E. A., Morton, J. D., Dawson, C. O., and Sedcole, R. 2009. Optical properties of raw and processed fish roes from six commercial New Zealand species. J. Food Eng. 91: 363-371.

Blasco, J., Aleixos, N., and Molto, E. 2003. Machine vision system for automatic quality grading of fruit. Biosyst. Eng. 85(4): 415-423.

Bledsoe, G., and Rasco, B. 2006. Caviar and fish roe. In: Handbook of Food Science, Technology, and Engineering. Hui, Y. H. (Ed). Boca Raton, FL: CRC Press.

Brosnan, T., and Sun, D. W. 2002. Inspection and grading of agricultural and food products by computer vision systems-A review. Comput. Electron. Agr. 36: 193-213.

Brosnan, T., and Sun, D. W. 2004. Improving quality inspection of food products by computer vision-A review. J. Food Eng. 61: 3-16.

Croft, E. A., de Silva, C. W., and Kurnianto, S. 1996. Sensor technology integration in an intelligent machine for herring roe grading. IEEE-ASME T. Mech. 1(3): 204-215.

Fabbri, R., Costa, L. F., Torelli, J. C., and Bruno, O. M. 2008. 2D Euclidean distance transform algorithms: A comparative survey. ACM Comput. Surv. 40(1): 2-1-2-44.

Gunasekaran, S. 1996. Computer vision technology for food quality assurance. Trends Food Sci. Tech. 7: 245-256. 
Kurnianto, S., de Silva, C. W., Croft, E. A., and Gosine, R. G. 1999. Intelligent automation of herring roe grading. In: Intelligent Adaptive Control: Industrial Applications. Jain, L. C. and de Silva, C. W. (Eds). Boca Raton, FL: CRC Press.

Luzuriaga, D., Balaban, M. O., and Yeralan, S. 1997. Analysis of visual quality attributes of white shrimp by machine vision. J. Food Sci. 62(1): 1-7.

National Marine Fisheries Service. 2009. Fisheries statistics \& economics: Foreign trade information. Retrieved September 9, 2009 from http://www.st.nmfs.gov/st1/trade/index.html

National Marine Fisheries Service. 2010. FishWatch. Retrieved September 27, 2010, from http:// www.nmfs.noaa.gov/fishwatch/species/walleye_pollock.htm

Tan, J. 2003. Meat quality evaluation by computer vision. J. Food Eng. 61: 27-35. 